\title{
LOW TOTAL CHOLESTEROL SERUM LEVELS AS A POOR OUTCOME PREDICTOR FOR INTRA-CEREBRAL HEMORRHAGE STROKE
}

\author{
I Gusti Agung Gede Ariswanda ${ }^{1}$, I Made Oka Adnyana ${ }^{1}$, I Putu Eka Widyadharma ${ }^{1}$, A A B N Nuartha ${ }^{1}$, A A A Putri \\ Laksmidewi ${ }^{1}$, I Komang Arimbawa ${ }^{1}$ \\ Correspondence: okaadnyanadrsps@yahoo.com \\ ${ }^{1}$ Department of Neurology, Medical Faculty of Udayana University, Sanglah General Hospital Bali, Indonesia
}

\section{Article History:}

Received: September 27, 2019

Accepted: June 15, 2020

Published: July 1, 2020

\section{Cite this as:}

Ariswanda IGAG, Adnyana IMO, Widyadharma IPE, Nuartha $A A B N$ Laksmidewi AAAP, Arimbawa IK. Low total cholesterol serum levels as a poor outcome predictor foor intracerebral hemorrhage stroke. Malang Neurology Journal; 2020.6:70. http://dx.doi.org/10.21776/ub.mnj.202 0.006 .02 .4

\section{ABSTRACT}

Background: Stroke is affected by several factors, age, infection during treatment, obesity, and total cholesterol (TC) levels.

Objective: The study aimed to prove low TC serum levels as an unfortunate outcome predictor for intracerebral hemorrhage stroke.

Methods: This study is a prospective cohort design. The research did in the Stroke Unit of Sanglah Hospital, Denpasar, from July 1st, 2018 to January 31th, 2019. The study involved patients with hemorrhage strokes with low TC serum levels and aged 40-95 years. Depending on variable divided into two groups with low TC serum levels $(<180 \mathrm{mg} / \mathrm{dL})$ and normal TC serum levels $(>180 \mathrm{mg} / \mathrm{dL})$. Independent variable is The National Institutes of Health Stroke Scale (NIHSS) as an outcome. The processing of data analysis using Mac for SPSS version 23.

Result: This study used 70 subjects. The age characteristics of the study subjects with a median value of 62 years in for low TC levels, and 57 years for normal TC levels, dominant in male (60\%), working (71.5\%), not obese $(58.6 \%)$, stroke-related infections $(51.4 \%)$, and mean arterial blood pressure (MABP) £130mmHg (90\%). Subjects with low TC had a risk of 64 times experiencing adverse outcomes $(\mathrm{RR}=64: \mathrm{CI} 95 \%=14.06-291.32: \mathrm{p}<0.001)$. Multivariate analysis showed a low TC serum level as an independent variable.

Conclusion: Low TC serum levels as an independent predictor having a poor outcome in intracerebral hemorrhage stroke

Keywords: Intracerebral hemorrhage stroke, low total cholesterol, poor outcome.

\section{Introduction}

Stroke is a non-communicable chronic disease that often found in the community with old adulthood. Blood pressure, serum blood sugar levels, and controlled serum cholesterol levels play an essential role in determining post-stroke prognosis. TC serum levels significantly influence the mortality rate of stroke patients within three months after the onset of a bleeding stroke. ${ }^{1}$

Nagasari Stroke Unit of Sanglah Hospital gained as much as 661 stroke patients consisted of $439(66.4 \%)$ male patients and $222(33.6 \%)$ female patients in the period from July 1st, 2018 to January 31th, 2019. ${ }^{2}$ Aged < 40 years were $51(7.7 \%)$ sufferers, aged 41-50 years were $140(21.2 \%)$ patients, aged 51-60 years were $208(31.5 \%)$ sufferers, and over the age of 60 in $262(39.6 \%)$ sufferers. The number of patients with hemorrhagic strokes was $246(37.2 \%)$ patients, and blockage strokes were $415(62.8 \%)$ patients. Mortality among stroke patients with hemorrhagic is twice that of ischemic stroke. ${ }^{3}$ The average length of stay for a hemorrhagic stroke patient was 7.7 days with a stay cost of $\$ 15.256$ while the price of a stroke patient who survived was higher by $\$ 17,442$ with an average stay of 9.6 days. ${ }^{4}$

\section{Methods}

This research was observational analytic using a design study prospective cohort of pre- and post-test to see two groups of research subjects who had low and normal TC serum. The study did at Department of Neurology, Medical Faculty of Udayana University, Sanglah General Hospital Bali, Indonesia. The sample from a hemorrhagic stroke who underwent treatment at Sanglah Hospital in July, 1st 2018January, 31th 2019 with criteria inclusion and exclusion. The inclusion criteria in this study were: (1) All supratentorial (2) Age 40-95 years, (3) Onset $\leq 48$ hours, (4) Patients or families agree to participate in this study after being given approval after explanation (5) Volume <30 ml (6) Midline shift $<4 \mathrm{~mm}$. (7) TC level $<180 \mathrm{mg} / \mathrm{dL}$. (8) Hypertension. (9) Normal hemostasis (10) Composmentis. Exclusion criteria were: (1) Patients with traumatic brain injury, (2) Patients with history of statins, alcohol and drug use , (3) Patients without Computer Tomography (CT) examination of the head, ( 4) Patients with brain tumors (5) Impaired organ function: heart, lung, kidney and liver, (6) Diabetes Mellitus, (7) Patients with metabolic disorders: hypoalbumin, electrolyte imbalance (9) Patients on chemotherapy or radiotherapy, (10) Vegetarian. The instrument used in this 
study consisted of a questionnaire. Questionnaires and data collection sheets were used to record basic data on patient characteristics, and the results of NIHSS examinations for the first and seventh day of treatment. A bad outcome is an increase in the NIHSS-2 score against a permanent NIHSS-1, $\square$, or death. Good outcomes found to decrease the NIHSS-2 score against NIHSS- 1 by a difference of $\square 2.5$ Analisis the data with SPSS for Mac version 23.

\section{Results}

Table.1 Characteristics of Research Subjects

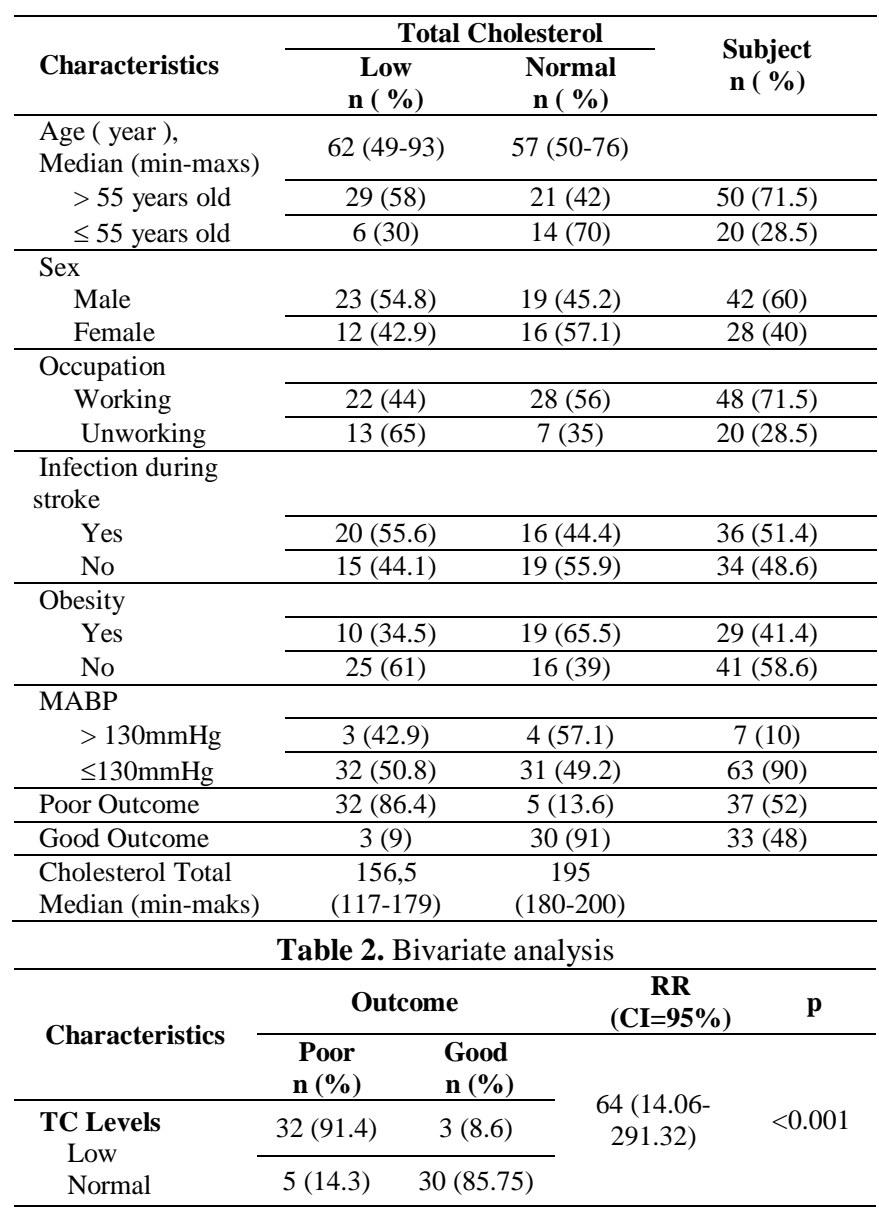

\section{Discussion}

The group of subjects with hemorrhagic stroke with poor outcomes was found more in the group of low TC serum levels of 32 people $(91.4 \%)$ compared to the normal TC serum levels of 5 people $(14.1 \%)$. In contrast, the group of stroke patients with good outcomes was found more in the whole TC serum group of 30 people $(85.7 \%)$ compared to the low TC serum level of 3 people $(8.6 \%)$.

Inthe Chi-Square test with continuity correction get a significant relationship $(R R=64:$ CI 95\% $=14.06-291.32: \mathrm{p}$ $<0.001)$. Patients with hemorrhagic strokes with low serum TC levels are 64 times more likely to experience bad outcomes than normal serum TC levels. Neuroradiology researcher found multifocal hypointense lesions in T2weighted Magnitude Resonance Imaging (MRI) as a marker of small bleeding associated with low TC serum levels. The profile of low TC serum levels is associated with the risk of death in stroke patients as evidenced by the presence of multifocal lesions on MRI images with $\mathrm{p}<0.05$. ${ }^{6}$

Research Roquer et al. (2005) obtained different results from researchers. This difference occurs due to differences in research methods, sample size, inclusion and exclusion criteria, and dependent variables. Researchers used a prospective cohort design with a sample size of 70 subjects divided into groups of low and normal TC serum levels with a cut value of $180 \mathrm{mg} / \mathrm{dL}$, the difference between NIHSS-1 and NIHSS-2 outcomes as the dependent variable. In the study of Roquer, et al. (2005), using a retrospective cohort study design, with a sample size of 184 subjects divided into groups of serum TC levels cut values of $166 \mathrm{mg} / \mathrm{dL}$, with death outcomes as the dependent variable. ${ }^{7}$ Serum TC levels are low as independent variables, and mortality outcomes are a dependent variable. Statistical analysis found that the group of low TC serum levels ( $<166 \mathrm{mg} / \mathrm{dL})$ might have a risk of death 3 times greater than the group of TC levels (> $166 \mathrm{mg} /$ $\mathrm{dL})$ with a value of $\mathrm{p}=0.002(\mathrm{HR}=3.13 ; 95 \% \mathrm{CI}=0,83$ 11.08). Decrease in low serum TC levels within 24 hours of a hemorrhagic stroke to date is unclear. ${ }^{7}$

Research Ramírez et al. (2009) shows that low serum TC levels are closely related to increased mortality in ICH strokes, and are increasing at the age of 70-89 years. Setianto et al. (2015), high C-Reactive Protein (CRP) is also poor outcome in ICH Stroke. ${ }^{8}$ Raisa et al. (2018), there were no influences between Glial Fibrillary Acidic Protein (GFAP) and ICH Stroke outcome. ${ }^{9}$ In prospective studies in Japan, morbidity and mortality increased in patients with serum TC levels $<160 \mathrm{mg}$ / dL or LDL-C levels <80 mg / dL. ${ }^{10}$

In the study of Iribarren, et al. (1995) by comparing two groups of low TC serum ( $<180 \mathrm{mg} / \mathrm{dL}$ ) with normal serum TC groups (180-239 mg / dL). Outcomes of death obtained by a hemorrhagic stroke with low TC serum levels had a risk 2.41 times more likely to die than the normal serum TC group $(95 \% \mathrm{CI}=1.45-4.00 ; \mathrm{p}<0.001) .{ }^{11,12} \mathrm{TC}$ serum needed for the continuation of intracellular chemical processes. The combination of low TC serum and triglyceride levels has an important role in maintaining the integrity of cellular membranes. Erythrocyte membrane damage (fragility), decreased platelet aggregation function in vivo and in vitro due to low TC levels play a role in poor treatment outcomes. ${ }^{13}$ Low serum total cholesterol levels also cause reduced endothelial adhesion power in arteries, loss of communication, and weak inter-cell linkages, and increased the length of time needed for the regeneration of blood vessel walls. ${ }^{14}$ A chronic weakness of the artery walls, which can trigger the emergence of microaneurysms. ${ }^{15}$

Research Chen et al. (2017) found groups with serum TC levels of $160 \mathrm{mg} / \mathrm{dL}$ had almost twice the risk of having a bad outcome with an NIHSS > 15, and three times more deaths in the three months after a stroke than the TC group > $200 \mathrm{mg} / \mathrm{dL}{ }^{1}$ In the study of Chen et al. (2017) using a retrospective cohort method, the chronology of death three months after stroke derived from family information. The Taiwan Stroke Registry data consists of 39 Government Hospitals with a stroke unit service. The total sample recorded as stroke sufferers from the period May 1, 2006 April 30, 2009, was 4000 patients. Inclusion criteria that a head injury did not cause all stroke patients with hemorrhagic. Stroke patients with post-stroke blockage excluded so that only 2444 stroke patients met the inclusion 
criteria. The independent variable used serum TC levels $<160$ $\mathrm{mmHg}$ and $>200 \mathrm{mmHg}$. NIHSS treatment outcomes with a cut value of $>14$, and Modified Rankin Scale (MRS) with a cut value of $>2$, and mortality three months post-stroke. Chen et al. (2017) research results differ from researchers due to differences in study designs. ${ }^{1}$ Chen et al. (2017) used a retrospective cohort method, while researchers used a prospective cohort. Samples used by researchers according to inclusion criteria, serum TC levels in researchers used a cut value of $<180 \mathrm{mg} / \mathrm{dL}$ as a treatment group and 180$200 \mathrm{mg} / \mathrm{dL}$ as a control group. Research Chen, et al (2017) with a cut value of $<160 \mathrm{mg} / \mathrm{dL}$ in the treatment group and $>200 \mathrm{mg} / \mathrm{dL}$ as a control group. Sample size, researchers used 70 hemorrhagic stroke patients, while Chen et al. (2017) 2444 patients (1). Stroke outcomes in researchers used the NIHSS instrument on the first and seventh day of treatment. The difference in points between NIHSS-1 and NIHSS-2 according to the operational definition categorized as a dependent variable on a nominal scale in both good and bad outcomes. Chen et al. (2017), using three instruments as a bad outcome. NIHSS with a cut value of $>14$ as a bad outcome assessed only on the first day of treatment, MRS with a cut of $>2$ experiencing disability disruption, and three months of death post-stroke. The difference in the use of NIHSS care scores, the difference in the cut of NIHSS scores, causes the results of the study to differ from those of Chen et al. (2017). Researchers get a group of TC serum levels $<180 \mathrm{mg} / \mathrm{dL}$ possibility of risk 64 times more likely to have worse outcomes than the group TC serum 180-200mg /dL. Research Chen et al., (2017) found a group with low serum TC levels $<160 \mathrm{mg} / \mathrm{dL}$ have a risk of death two times greater than the group of serum TC levels $>200 \mathrm{mg} / \mathrm{dL} .{ }^{1}$ Munir $e t$ al. (2015) NIHSS and random blood sugar have been not a relationship for stroke outcome. ${ }^{16}$

NIHSS as a predictor of death 30 days after a stroke obtained on the first day of treatment with a cut value of $>20(0-20$ vs.> 20). NIHSS has a sensitivity of $81 \%$ and a specificity of $90 \% .{ }^{17}$ In this study using NIHSS as the first and seventh day hemorrhagic stroke output instruments with different NIHSS1 and NIHSS- 2 scores according to the operational definition and not using a cut of $>20$ as an adverse outcome.

Based on multivariate analysis, low TC serum found as an independent risk factor for treatment outcomes. Hemorrhagic stroke sufferers are likely to have a 64 times greater risk of experiencing an adverse outcome compared to patients with normal TC TC levels $(\mathrm{RR}=64 ; 95 \% \mathrm{CI}=14.01-291.3 ; \mathrm{p}$ $<0.001)$.

\section{Conclusion}

Low TC serum levels as an independent predictor having a poor outcome in intracerebral hemorrhage stroke

\section{Conflict of Interests}

There were no financial supports or relationships between authors and any organizations or professional bodies that could pose any conflict of interest.

\section{Acknowledgement}

The author, thanks Udayana University and Sanglah General Hospital, Denpasar, Bali Indonesia, for facilitating this research.

\section{References}

1. Chen YW, Li CH, Yang CD, Liu CH, Chen $\mathrm{CH}$, Sheu JJ, et al. Low cholesterol level associated with severity and outcome of spontaneous intracerebral hemorrhage: Results from Taiwan Stroke Registry. PloS one; 2017. 12(4):1-15. DOI: 10.1371/journal.pone.0171379

2. Wangi, Widyadharma, Adnyana. proporsi dan karakteristik penderita stroke di unit stroke Nagasari RSUP Sanglah Denpasar periode Januari 2012Desember 2014 - Google Search [Internet]. [cited 2019 Jun 30].

3. Wong GKC, Lam SW, Poon WS. Long Term Outcome after Hemorrhagic Stroke Surgery (LOMSS) in Hong Kong Chinese. Journal of Advances in Medicine and Medical Research; 2013. 182-88. DOI: 10.9734/BJMMR/2013/1717

4. Russell MW, Joshi AV, Neumann PJ, Boulanger L, Menzin J. Predictors of hospital length of stay and cost in patients with intracerebral hemorrhage. Neurology; 2006. 67(7):1279-81.

DOI: 10.1212/01.wnl.0000238349.28146.46

5. Kazemnejad-Leili E, Rezaei S, Hosseini-Nejad M, Bakhshayesh-Eghbali B, Saberi A, Keshavarz P. the applicability, concurrent validity and internal consistency reliability of the persian version of the National Institutes of Health Stroke Scale (NIHSS): evidences for gender differences. Caspian Journal of Neurological Sciences; 2016. Mar;1(2):18-8.

DOI: 10.18869/acadpub.cjns.2.4.18

6. Ramírez-Moreno JM, Casado-Naranjo I, Portilla JC, Calle ML, Tena D, Falcón A, et al. Serum cholesterol LDL and 90-day mortality in patients with intracerebral hemorrhage. Stroke; 2009. May;40(5):1917-20.

DOI: 10.1161/STROKEAHA.108.536698

7. Roquer J, Campello AR, Gomis M, Ois A, Munteis E, Böhm P. Serum lipid levels and in-hospital mortality in patients with intracerebral hemorrhage. Neurology; 2005. 65(8):1198-1202.

DOI: 10.1212/01.wnl.0000180968.26242.4a

8. Setianto CA, Purnomo H, Marhaendraputro EA, Santoso WM. Correlation of c-reactive protein levels with clinical outcome intracerebral hemorrhage stroke patients. Malang Neurology Journal; 2015. 1(1):23-7. Available https://mnj.ub.ac.id/index.php/mnj/article/view/19

9. Raisa N, Sujuti H, Purnomo H, Rahayu M, Dalhar M. The influence of sampling time to serum Glial Fibrillary Acidic Protein (GFAP) levels in acute stroke. Malang Neurology Journal; 2018. 5(1):30-3. Available from: https://mnj.ub.ac.id/index.php/mnj/article/view/358

10. Cholesterol Treatment Trialists' (CTT) Collaboration, Baigent C, Blackwell L, Emberson J, Holland LE, Reith $\mathrm{C}$, et al. Efficacy and safety of more intensive lowering of LDL cholesterol: A meta-analysis of data from 170,000 participants in 26 randomised trials. Lancet; 
11. 2010. Nov;376(9753):1670-81. DOI: $10.1016 / \mathrm{S} 0140-$ 6736(10)61350-5

12. Iribarren C, Reed DM, Burchfiel CM, Dwyer JH. Serum total cholesterol and mortality. Confounding factors and risk modification in Japanese-American men. JAMA; 1995. Jun 28;273(24):1926-32. Avalaible from : https://www.ncbi.nlm.nih.gov/pubmed/7783302

13. Huhle G, Abletshauser C, Mayer N, Weidinger G, Harenberg J, Heene DL. Reduction of platelet activity markers in type II hypercholesterolemic patients by a HMG-CoA-reductase inhibitor. Thrombosis research; 1999. 95(5):229-34. DOI: 10.1016/s00493848(99)00037-7

14. Kaneider NC, Egger P, Dunzendorfer S, Wiedermann CJ. Rho-GTPase-Dependent Platelet-Neutrophil interaction affected by HMG-CoA reductase inhibition with altered adenosine nucleotide release and function. Arteriosclerosis, Thrombosis, And Vascular Biology; 2002. 22(6):1029-35.

DOI: $10.1161 / 01 . A T V .0000018306 .68268 .86$
15. Jellinger P, Smith D, Mehta A, Ganda O, Handelsman Y, Rodbard H, et al. American Association of Clinical Endocrinologists' guidelines for management of dyslipidemia and prevention of atherosclerosis. Endocrine practice; 2012.18(Supplement 1):1-78. DOI: $10.4158 /$ ep.18.s1.1

16. Munir B, Rasyid HA, Rosita R. Relationship between the random blood glucose levels during admission at emergency room with clinical output in acute ischemic stroke patients. Malang Neurology Journal; 2015 Jun;1(2):52-60. Available from: https://mnj.ub.ac.id/index.php/mnj/article/view/21

17. Cheung CM, Tsoi TH, Hon SF, Au-Yeung M, Shiu KL, Lee $\mathrm{CN}$, et al. Using the National Institutes of Health Stroke Scale (NIHSS) to predict the mortality and outcome of patients with intracerebral haemorrhage. Hong Kong Med J; 2008.14(5):367-370. Avalaible from: https://www.ncbi.nlm.nih.gov/pubmed/18840907 